\title{
Long-Term Monitoring of Green Turtle Nesting on Tromelin Island Demonstrates Stable Reproduction and Population Parameters
}

\author{
Derville Solène ${ }^{1,2}$, Jean Claire ${ }^{2}$, Dalleau Mayeul ${ }^{2}$, Le Gal Jean-Yves ${ }^{3}$, Ciccione Stéphane ${ }^{2}$, \\ Bourjea Jérôme ${ }^{4,5, *}$
}

${ }^{1}$ Univ Lyon, UCB Lyon1, Ecole Normale Super Lyon, Dept Biol, Lyon, France.

2 Kelonia, Observ Tortues Marines La Reunion, St Leu 97436, Reunion.

${ }^{3}$ ENSAgro, F-35042 Rennes, France.

4 IFREMER, Delegat Ocean Indien, Le Port 97822, Reunion.

${ }^{5}$ Univ Reunion IsI, CNRS, INEE FRE3560, St Denis 97715, Reunion.

*Corresponding author : Jérôme Bourjea, email address : Jerome.Bourjea@ifremer.fr ;

solene.derville@ens-lyon.fr ; clairejean@kelonia.org ; mayeuldalleau@kelonia.org ; iyfrlegall@yahoo.fr ; stephaneciccione@kelonia.org ;

\begin{abstract}
:
Situated about $500 \mathrm{~km}$ off the Malagasy east coast, the island of Tromelin is a key nesting site for the endangered green turtle, Chelonia mydas, in the south Western Indian Ocean. Nesting turtles found in this isolated island have been closely monitored since the 1970s, but the most recent estimates of nesting parameters date from 1986. Using mark-recapture data, track counts, and nests monitoring data collected over the 2009/2010 nesting peak, reproductive characteristics, population size, and offspring production were updated and discussed in the light of the track survey undertaken from 1986 to 2010. Females showed a consistent reproductive behaviour compared with previous studies in terms of clutch frequency $(2.75+/-1.46)$ and nesting success $(0.65)$. Nest indices such as hatching success $(0.76+/-$ $0.25)$ and emergence success $(0.61+/-0.33)$ were also included in the range of values calculated in the 1980s. Importantly, the estimated number of nesters and production in eggs and hatchlings were similar to older estimates, suggesting a relative demographic stability. For the 2009/2010 year-long nesting season, the size of the nesting population was estimated at about 1500 individuals, which produced around 480,900 eggs (+/- 103,900), resulting in 289,200 emerging hatchlings $(+/-152,000)$. These results are promising and support the effectiveness of conservation measures undertaken in the lles Eparses, but further comparable monitoring is needed in the coming years to confirm the stability in Tromelin's green turtle nesting population.
\end{abstract}

Keywords : Reptilia, Testudines: Cheloniidae, Chelonia mydas, green turtle, nesting activity, population assessment, Indian Ocean, Tromelin Island 
The green turtle (Chelonia mydas) is one of the seven species of marine turtles that use tropical and subtropical waters worldwide. Anthropogenic pressure on green turtles can be particularly high in some places of the world (Mast et al. 2005; Broderick et al. 2006; Wallace et al. 2011) including destruction of both nesting and feeding habitats (Hughes et al. 2009; Fuentes et al. 2011) or as a result of direct impact due to bycatch in fisheries and longstanding overexploitation of eggs and meat (Allen 2007; Wallace et al. 2010). For these reasons, this species has been classified as globally endangered in the IUCN Red List (IUCN 2014). The conservation of any threatened animal population relies on the estimation of the number of breeders, their reproductive success (i.e., number of fertile offpsring an individual produces) and the temporal evolution of these estimates. However, marine turtles, and more specifically green turtles, are hard to monitor because of their complex life history that includes several stages that differ in terms of diet, sexual behaviour and habitat. After about one to ten years at sea (Avens and Snover 2013), green turtle juveniles enter neritic feeding habitats were they stay until they reach maturity (Arthur et al. 2008). Following this stage, females often migrate hundreds of kilometres from their feeding grounds to their nesting site to breed (Bowen and Karl 2007). Reproduction takes place on average every 3 to 4 years and results in the laying of several clutches per nesting season (Miller 1997). Many environmental and physiological factors, such as sand characteristics, temperatures or body condition can affect this nesting process (Mortimer 1990; Pike 2008). As a consequence, a female emergence on the beach does not necessarily lead to a clutch and individuals may make several attempts before actually laying eggs (Mortimer 1990; Limpus et al. 2003). A successful nesting is followed by an incubation of about 2 months, after which hatchlings emerge from the nest and quickly crawl to the water. Here again, environmental factors have an impact on hatching and emergence, while predation may also result in severe losses (Mortimer 1990; Ackerman 1997). Collecting data on reproduction is crucial in the estimation of parameters such as clutch frequency (number of clutches laid per female), nesting success (ratio of successful nesting to total female emergences), clutch size (number of eggs per clutch), hatching and hatchling emergence rates. These reproductive parameters are key to understanding marine turtle population dynamics.

During the last century, local conservation measures established on the basis of population assessments have allowed the partial but encouraging recovery of many rookeries (Broderick et al. 2006). However, the size of reproductive populations is highly variable from one site and one year to another and research programs undertaken in the Western Indian Ocean have all underlined the importance of continual monitoring in the region: namely the 
Comoros Archipelago and Mayotte (Bourjea et al. sub. a; Bourjea et al. 2007; Frazier 1985), Reunion Island (Ciccione and Bourjea 2006), Madagascar (Bourjea et al. 2006), Seychelles (Mortimer 1988, 2012; Mortimer et al. 2011), Mozambique (Garnier et al. 2012), and the Scattered Islands (or « Iles Eparses ») (Le Gall et al. 1985; Le Gall et al. 1986; Bosc and Le Gall 1986; Le Gall and Hughes 1987; Lauret-Stepler et al. 2007; Bourjea et al. 2011).

Among these study sites, the Iles Eparses are five islands under French jurisdiction scattered around Madagascar. All of these islands host marine turtles, as green turtle nesting sites (Europa, the Glorieuses, Juan de Nova, Tromelin) and/or as development habitats for green and hawksbill turtles (Europa, the Glorieuses, Juan de Nova; Bourjea et al. 2011). They were declared protected areas in the 1970s (DIREN 2003) and since then green turtle populations of those islands have been closely protected and monitored (Lauret-Stepler et al. 2007). Flipper tagging studies undertaken between 1971 and 1984 and track counts carried out throughout the last 40 years have highlighted the importance of Tromelin for green turtle breeding and nesting activities all year round (Batori 1974; Hughes 1974, 1982; Vergonzanne et al. 1976; Le Gall et al. 1985, 1986; Bosc and Le Gall 1986; Lauret-Stepler et al. 2007; Bourjea et al. 2011). In contrast to the Glorieuses and Europa where the annual number of tracks has consistently increased since 1986, the trend in Tromelin population size between 1986 and 2006 remains unclear (Bourjea et al. 2011). Even if Tromelin is a quasi-pristine island, its green turtle nesting population is vulnerable to perturbations because of its geographical isolation (Jennings 2000). An increase of threats at sea or on foraging grounds could have dramatic consequences on the population and reproductive output of the rookery (Dalleau 2013). Reliable estimates of the breeding population's size and productivity are required to determine population status and establish conservation measures to mitigate any possible decline.

Using mark-recapture data, track counts and nest monitoring data collected over the 2009/2010 nesting season, we performed an estimation of reproductive parameters (i.e. nesting characteristics and clutch size and fate), population size and egg and hatchling production. In order to perform a reliable comparison of indices and estimates across time, we selected field protocols and calculation methods as close as possible to the ones used previously from 1973 to 1984 (Le Gall et al. 1985, 1986; Bosc and Le Gall 1986).

\section{METHODS}

Study Site.-Tromelin ( $15^{\circ} 53^{\prime} \mathrm{S}$ and $\left.54^{\circ} 31^{\prime} \mathrm{E}\right)$ is a remote coral island located $500 \mathrm{~km}$ off the East coast of Madagascar and $600 \mathrm{~km}$ North of Reunion Island (Fig. 1). Tromelin (1 
$\mathrm{km}^{2}$ ) is one of the islands known collectively as Iles Eparses, a French overseas territory since 1960 and a protected area since 1971. Before a small weather station was built in 1954, only a few slaves had inhabited the island after the wrecking of a French ship in 1761. The Knight of Tromelin rescued survivors 15 years later and the island has borne the name of the vessel since then (Frain 2009). The southeastern coast of Tromelin is covered with coral rocks whereas its northwestern and southwestern coasts form a single coral sand beach sheltered from the wind (Fig. 1). Green turtles, the only species known to nest on this island, do so year-round with a nesting peak in January (Le Gall et al. 1985, 1986; Lauret-Stepler et al. 2007; Dalleau et al. 2012). There is a high level of protection against anthropogenic threats on Tromelin: neither poaching nor bycatch have been reported within the protected area (LauretStepler et al. 2007). Vegetation is very sparse on the island, mainly bushes (e.g. Tournefortia argentea), with some herbaceous vegetation and creeping plants (e.g. Portulaca oleracea) (Marriner et al. 2010). The periodic use of rodenticides has controlled the only mammals present in the area, the house mouse (Mus musculus), and the brown rat (Rattus norvegicus) (Le Corre and Safford 2001), the latter having been eradicated in 2005 (Russell and Le Corre 2009). Two species of sea birds currently nest on the island (i.e. Redfooted Booby Sula sula and Masked Booby $S$. dactylatra) but were not found to predate emerging hatchlings (Le Corre 1996;. Le Corre, pers. com). Aerial predation is mainly due to a few frigate birds (i.e. Fregata minor) which use the island as a resting site (Le Corre and Jouventin 1997). It is worthwhile noting that Tromelin also hosts a great number of terrestrial hermit crabs (Coenobita perlatus, Le Gall and Poupin n.d.) which feed intensively on turtle hatchlings and eggs.

Data Collection. - Since 1986, turtle tracks have been monitored daily on Tromelin by trained staff members from the Terres Australes et Antarctiques Françaises (TAAF) or Météo-France and occasional research teams. The number of descending tracks was recorded every morning before high tide following the international standard procedure (Schroeder and Murphy 1999). The total seasonal number of tracks was obtained by adding up track counts between April of a given year and March of the following year. Occasional gaps in seasons $1986 / 1987$ to $2008 / 2009$ were filled by data interpolation following the method presented in Dalleau et al. (2012). During the 2009/2010 nesting season, monitoring effort was $98.6 \%$ (i.e. 360 days out of 365 ) and no interpolation was made for the remaining 1.4\%.

Mark-recapture monitoring of nesting females was undertaken on Tromelin from 15 April 2009 to 15 April 2010. Trained surveyors patrolled the beach every night starting two 
hours before high tide. Biometrics measurements (Curved Carapace Length - CCL; Bolten 1999) were carried out as well as flipper tagging following international standard protocols (Balazs 1999). When encountered for the first time, a turtle was tagged with a 'Monel' metal tag (1005-49 Monel ${ }^{\circledR}$ tag TRO) on the front left flipper or the right one if the left flipper tagging site was unsuitable. During recapture, the tag number was recorded and condition of the tag was checked.

Nests monitoring was carried out during eight months from the beginning of June 2009 to the beginning of January 2010. Randomly chosen nests were protected with a onemetre high circular wire enclosure, to prevent the intrusion of predators (e.g. hermit crabs and sea birds). They were checked regularly during the days preceding the expected time of emergence (i.e., starting forty days after clutch laying). Hatchling emergences occurred from August 2009 to the beginning of March 2010 and the number of hatchlings inside the fences was counted before release. Excavation took place approximately 72 hours after the beginning of the emergence and the number of empty shells was counted along with any living hatchlings left among shells, the dead hatchlings in the nest, the un-hatched eggs and the depredated eggs following international standard protocols (Miller 1999).

Calculating Nesting Characteristics.-To ensure consistency with the study design of Le Gall et al. (1985, 1986), nesting characteristics were calculated over a mark-recapture subdataset restricted to a 3-month long period centred on the median nesting peak date (i.e. from 8 December 2009 to 8 March 2010) hereafter referred to as the '2009/2010 nesting peak'. Following Dalleau et al. (2012), the median nesting peak date was fixed at 22 January 2010. For accurate estimation over an entire year-long nesting season, nesting characteristics were computed using the same methods over the whole available mark-recapture dataset (i.e. from mid-April 2009 to mid-April 2010) hereafter referred to as the '2009/2010 nesting season'.

A re-capture interval was defined as the elapsed time (in days) between two successive sightings of a given individual (Le Gall et al. 1985, 1986). For each female captured more than once, we computed a set of recapture intervals, which were subsequently pooled over all individuals. Modes in the pooled recapture intervals distribution were then estimated by piecewise averaging, using the distribution local minima as breakpoints.

For a given female, the ratio of successful emergences with total emergences on the beach constitutes the individual nesting success (Alvarado and Murphy 1999). In practice, it is not always possible to ascertain that a female has laid a clutch when encountered on the beach because (1) the tracks may not be interpretable (2) it might require a long wait which will result in the missing of other individuals. Similar to Le Gall et al. $(1985,1986)$ we choose 
to estimate the population nesting success (NS) as the ratio between the number of re-capture intervals greater than eight days and the total number of re-capture intervals calculated over the population. This calculation is made under the assumption that intervals inferior to 8 days result from failed nesting attempts ('N( )' stands for 'the number of'):

$$
N S=\frac{N(\text { intervals } \geq 8 \text { days })}{\text { Total } N(\text { intervals })}
$$

The total number of nests was estimated as the product of the population nesting success by the number of tracks:

$$
N(\text { nests })=N S \times N(\text { tracks })
$$

The individual clutch frequency is defined as the number of clutches laid by a female during a nesting season (Alvarado and Murphy 1999). For a given female $i$, it was estimated from the number of times the turtle $i$ had been sighted and the re-capture intervals between these sightings. The population clutch frequency (CF) was averaged over all individual clutch frequencies:

$$
C F=\operatorname{mean}\left[N_{i}(\text { captures }) \times \frac{N_{i}(\text { intervals } \geq 8 \text { days })}{\text { Total } N_{i}(\text { intervals })}\right]
$$

Calculating Clutch Size and Fate.-Nest indices were calculated for every monitored nest then averaged for comparison with Le Gall et al. (1985). Since no direct counting of the eggs was made during oviposition, clutch size (CS) was estimated from the sum of the number of empty shells (when at least half of the shell was found), unhatched and depredated eggs in an excavated nest. For a given nest:

$$
C S=N(\text { empty shells })+N(\text { unhatched eggs })+N(\text { depredated eggs })
$$

The hatching success is the ratio of hatchlings that hatch out of their eggshell (Miller 1999) whereas emergence success is the ratio of hatchlings that effectively reach the beach surface (Miller 1999). For a given nest: 


$$
\begin{gathered}
\text { Hatching success }=\frac{N(\text { empty shells })}{C S} \\
\text { Emergence success }=\frac{N(\text { emerged hatchlings })}{C S}
\end{gathered}
$$

Estimating Population Size and Production.-Population estimates were calculated over the 2009/2010 nesting peak for comparison with Le Gall et al. $(1985,1986)$ and over the whole 2009/2010 nesting season. Also, based on the reproductive characteristics of the 2009/2010 nesting season and tracks counts from 2004/2005 to 2009/2010, the number of nesting females was estimated seasonally over the last five years (with nesting season 2007/2008 and 2008/2009 being excluded due to a lack of track count data). This five-year period was chosen to cover the usual remigration interval of three to four years found in green turtles (Miller 1997).

We estimated the number of nesting females that came on site $(\mathrm{F})$ from the number of tracks and the nesting characteristics (Gerodette and Taylor 1999):

$$
F=N(\text { tracks }) \times \frac{N S}{C F}
$$

The total numbers of eggs and hatchlings produced were assessed as follows:

$$
\begin{gathered}
\text { Egg production }=N(\text { nests }) \times \text { Mean }(C S) \\
\text { Hatchling production }=N(\text { nests }) \times \text { Mean }(\text { emerged hatchlings })
\end{gathered}
$$

With associated standard deviation (SD) being calculated as the product of a variable $\mathrm{X}$ with constant a:

$$
S D(a X)=a \times S D(X)
$$

All data analysis and statistical modelling were performed using R statistical software version 3.0.2 (R Core Team 2013).

\section{RESULTS}

Track Surveys.-The seasonal number of tracks recorded from 1986 to 2010 showed a high degree of variability (Mean $=8101 ; \mathrm{SD}=2,830 ; n=20$ ), ranging from 4440 in 
$1995 / 1996$ to 14,427 tracks in $1986 / 1987$ (Fig. 2). With up to 7180 tracks, the $2009 / 2010$ nesting season lies within the interquartile range of all seasonal counts $(\mathrm{IQR}=3176)$ and is close to its median $($ Median $=7480)$.

Nesting Characteristics._-During the 2009/2010 nesting peak, 596 individual females were captured from which 424 were re-captured at least once and 4244 tracks were counted. Nesting characteristics estimated for the peak nesting period for this population are presented in Table 1. Also, for the entire 2009/2010 nesting season, population nesting success was estimated at 0.62 , total number of nests was estimated at 4417 and average population clutch frequency was $3.01(\mathrm{SD}=1.54, n=688)$.

A total of 1338 re-capture intervals were compiled for 424 turtles that had been captured at least twice during the 2009/2010 nesting peak (Fig. 3). Two main distribution modes were observed in the recapture intervals. The first peak included $35 \%$ of total intervals, ranging from zero to seven days long (average: $1.5 \mathrm{~d}$ ). These intervals clearly reflected the emergence of females which aborted their first nesting attempt and came back on the beach less than eight days later. The second peak was centred on 11.7 days and probably represented the average renesting interval between two consecutive successful nesting emergences ( $47 \%$ of total intervals). Other peaks of lesser range for longer re-capture intervals may result from the missing of successful emergences by the surveyors. There were 867 intervals greater than or equal to eight days.

Clutch Size and Fate.-There were 96 nests monitored during the 2009/2010 season and hatchling emergence was observed in 73 of them. The average number of hatchlings that emerged per nest was $65.5(\mathrm{SD}=34.4, n=73)$. Clutch size and hatching and emergence successes for these monitored nests are shown in Table 2.

Population Estimates. - Over the complete 2009/2010 nesting season we estimated that 1467 turtles emerged to nest on Tromelin, laying 480,901 eggs (SD = 103,899), resulting in an estimated emergence of 289,223 hatchlings $(\mathrm{SD}=152,027)$. Over the five seasons preceding 2009/2010 when enough data was available, the estimated number of nesting females ranged from 1241 in 2004/2005 to 1600 in 2006/2007 (Median=1535; IQR=179, $n=$ 3 ). The number of nesting females estimated on Tromelin during the 2009/2010 nesting peak and the resulting estimated number of eggs and hatchlings produced during this same time are presented in Table 3 and compared to Le Gall et al. $(1985,1986)$.

\section{DISCUSSION}


Reproductive Characteristics.-Because of their low position in the food chain (Godley et al. 1998), green turtle reproduction can be greatly affected by environmental variations on their feeding grounds (Carr and Carr 1970; Hays 2000; Broderick et al. 2001). As a consequence, green turtle nesting is highly variable from one year to the next and temporal trends are difficult to determine (Bjorndal et al. 1999; Jackson et al. 2008). Track counts (as a proxy for nesting activity) on Tromelin during the past 30 years have shown a great deal of annual variability (Fig. 2), as is commonly found in green turtle nesting populations (e.g., Northern Cyprus, Broderick et al. 2001). Indeed, a given population usually fluctuates between seasons of low and high nesting effort (Dalleau et al. 2012). The number of tracks during the 2009/2010 nesting season is on the same order of magnitude as the average track counts observed on Tromelin since 1986 (i.e. 7180 tracks in 2009/2010; Median $\left._{\text {long term }}=7480 ; \mathrm{IQR}_{\text {long term }}=3176, n=19\right)$, suggesting that 2009/2010 approximates an average year in terms of nesting activity. It has been reported that in years when fewer turtles nest they also have a lower reproductive success (e.g. decreased clutch frequency, Broderick et al. 2003), which suggests a correlation between nesting activity (estimated from track counts) and nesting characteristics (estimated from individual tagging) across years. Thus, 2009/2010 being an average year in terms of nesting effort, it is likely that nesting characteristics for this season approximate those of previous average seasons.

These nesting characteristics were estimated on Tromelin Island using mark-recapture of individuals emerging on the beach. The principal bias in mark-recapture sampling of large nesting populations is the inability to sight all emergences of every tagged turtle (Mortimer 1999; Rivalan et al. 2006). Tromelin Island is small enough to be completely surveyed on a nightly basis. Also, knowing that the closest beach to Tromelin is $450 \mathrm{~km}$ away (e.g. Madagascar), an individual that came on this island to nest is unlikely to lay clutches at other nesting sites during the same season. However, during the 2009/2010 nesting season, the total number of tracks (7180) was far greater than the number of observed female emergences from the mark-recapture data (3316). Hence, more than one out of two emergences was not recorded in the individual capture histories. The calculation methods for nesting characteristics used by Le Gall et al. $(1985,1986)$ are based on the distribution of re-capture intervals which minimizes this bias. Since we found the same distribution of recapture interval for the 2009/2010 nesting peak as Le Gall et al. (1985, 1986), it was appropriate to use the same calculation methods with this more recent dataset for the entire 2009/2010 season. Indeed, the comparison of reproductive characteristics across time can only be reliable if calculation methods, duration of study and period of year are the same. During the 
2009/2010 nesting peak, nesting characteristics (CF and NS) fell within the range that was observed in the 1980s (Table 1). Nesting emergences during the 2009/2010 nesting peak (4244) resulted in a relatively small number of nests for the same period (2750; Table 1). It is worth noting that the estimation of the population clutch frequency can be biased low if the monitoring period is too short, not allowing for turtles to be observed throughout their nesting sequence. For the sake of our comparative analysis we focused on a three-month long study period similar to the ones followed by Le Gall et al. $(1985,1986)$ although in absolute terms this period likely resulted in a slightly under-estimate of clutch frequency.

Widely accepted standard protocol (Miller 1999) currently exist for nest monitoring and determination of their fate (i.e. hatching and emergence successes). The main uncertainty lies in the estimation of clutch size, which can be achieved by various ways: (1) direct counting at oviposition (Le Gall et al. 1985; Limpus et al. 2003), (2) counting during the following days which requires excavation and being reburied (Le Gall et al. 1985; Bjorndal and Carr 1989; Cheng et al. 2009; Garnier et al. 2012) and (3) counting of empty shells after final excavation (Broderick et al. 2003; Mortimer 1990; our study). Adding up empty shells and unhatched eggs provides an estimate of the clutch size: however, this estimate contains counting errors due to the tearing of the shells during hatching. The mean clutch size from Le Gall et al. (1985) (132-136 eggs/nest SD 15.5-25.4) estimated with method 1) and 2) is higher than our 2009/2010 update (109 eggs/nest SD 23.5) (Table 2). Although the three methods provided similar results according to Le Gall et al. (1985), it is likely that the third method leads to an underestimate of clutch size which could, in part, explain the lower mean found for 2009/2010, even though a true decrease in clutch size cannot be fully rejected. Accordingly, the hatching and emergence successes in 2009/2010 would also be influenced by underestimated clutch sizes and therefore thought to be slightly overestimated compared to Le Gall et al. (1985). However, mean clutch size for 2009/2010 nearly falls within the known global scale average of 110 to 130 eggs per clutches for green turtles (Pritchard and Mortimer 1999) and subsequent hatching and emergence successes are well represented in the range of values reported in Le Gall et al. (1985).

Nesting Population Size and Offspring Production.-The estimated number of nesting females for the 2009/2010 nesting peak is in the range reported from 1973 to 1984 estimates (Table 3). However, a gap remains between 1984 and 2009 since no data are available for nesting characteristics during this period. Bjorndal et al. (1999) highlighted the impossibility to estimate the size of a nesting population only from track data when clutch frequency is unknown. Indeed, it is crucial to realize that even if the number of tracks found on a location 
is proportional to the number of reproductive females (Frazier 2012), the coefficient varies through time. Intra and inter annual variations in clutch frequency and nesting success have an obvious impact on the estimated number of nesting females, as well as eventual changes in the remigration intervals (Hays 2000). As a consequence, it is still impossible to be absolutely convinced on the evolution of the number of nesters between the 1980s' and the 2009/2010 nesting season, but the comparison of 2009/2010 population estimate to historical data suggests a demographic stability. Regular mark-recapture studies are needed to evaluate changes in nesting characteristics and improve the demographic trend analysis on the basis of track counts. The use of standard protocols over time and for similar periods within the nesting seasons is essential to undertake inter-annual comparisons and provide reliable trend analyses of nesting populations.

We estimated the nesting population size of Tromelin Island at about 1,500 females for the whole 2009/2010 nesting season. When using interpolated track counts from 2004 to 2009 (Dalleau et al. 2012) and using 2009/2010 nesting characteristics (i.e. NS and CF) we found a similar mean annual population size of about 1330 females. Yet, the number of nesting females is not the only important parameter to assess the stability of a turtle population. Offspring survival also greatly affects the long-term demography of rookeries and must not be neglected (Chaloupka 2001; Bolten et al. 2011). On Tromelin Island, about 481,000 eggs were produced and around 289,000 hatchlings were estimated to have emerged along the 2009/2010 nesting season. Even though standard deviation is large, the production in eggs during the 2009/2010 nesting peak seems low compared to Le Gall et al. (1985) probably because of the methodological differences in the estimation of clutch size (Table 2). In contrast, our estimation of the number of hatchlings for the same period is based on a separate approach using the mean number of hatchlings emerging per nest and is therefore not subjected to this clutch size bias. The estimated production in hatchlings and the associate variance during the 2009/2010 nesting peak is similar to what was observed by Le Gall et al. (1985) (Table 2). This is in favour of a relatively stable reproductive success of Tromelin's nesting population over time. We suggest that conservation plans should not only take into account the possible changes in nesting effort, but also the annual production of hatchlings which will affect the estimated population size over the long term.

\section{Conclusions}

Tromelin Island is a good example of a nesting site where turtles benefit from a high level of protection against anthropogenic threats while nesting (Lauret-Stepler et al. 2007) but 
where the population is still endangered when migrating between their feeding and nesting grounds and whilst on their feeding grounds. Female green turtles have been shown to migrate from Tromelin towards feeding habitats located along the Malagasy and East African coasts (Le Gall and Hughes 1987; Dalleau 2013). After being equipped with satellite tracking devices on Tromelin, only a few of them (28.5\%) migrated towards protected areas (Dalleau 2013). Even if marine turtles are protected under the Malagasy national law, green turtles are still threaten by traditional fisheries and local consumption (Bourjea et al. 2008; Bourjea et al. sub. b.; Humber et al. 2011). Turtle harvest in Madagascar was thought to reach 12,000 individuals in 1992 (Rakotonirina and Cooke 1994) and has probably stabilized around this level over the last several years (Humber et al. 2011). Growing human activity in the countries bordering the western Indian Ocean is also thought to accelerate the destruction of green turtle feeding habitats (Orth et al. 2006; Harris et al. 2010). Since female green turtles from many other nesting sites in this region share common feeding grounds (Dalleau 2013), Tromelin's nesting population may be an index population for measuring the impact of environmental changes and regional threats during migration or at foraging grounds. Because of its isolation, small surface area, sanctuary status and exposure to threats on mainland east Africa, Tromelin Island is a site of interest for green turtle conservation in the South Western Indian Ocean and warrants long-term monitoring for many years to come.

\section{ACKNOWLEDGEMENTS}

This study was financially supported by Kélonia, l'observatoire des tortues marines de La Réunion. All manipulations of animals were conducted in accordance with French legislation and under special dispensation delivered by the TAAF. The authors are most grateful to the TAAF and Météo-France staff for their inestimable involvement in the turtle tracks monitoring at Tromelin since the eighties. We especially thank the FAZSOI for carrying out field trips logistics and Kélonia staff members and volunteers who took part in the monitoring in 2009 and 2010. S.D. gratefully acknowledges the École Normale Supérieure of Lyon for its financial support. Lastly, we thank Georges R. Hughes, the handling Editor Jeffrey A. Seminoff and two anonymous reviewers for helpful comments and suggestions.

\section{LITERATURE CITED}


ACKERMAN, R. 1997. The nest environment and the embryonic development of sea turtles. In: Lutz P. and Musick J.A. (Eds.) The biology of sea turtles. Boca Raton, FL: CRC Press. pp. 83-106.

ALLEN, M.S. 2007. Three millennia of human and sea turtle interactions in Remote Oceania. Coral Reefs, 26, 959-970.

Alvarado, J. AND MurPhy, T.M. 1999. Nesting Periodicity and Internesting Behavior. In: Eckert, K.L., Bjorndal, K.A., Abreu-Grobois, A. F. and Donnelly, M. (Eds.). Research and Management techniques for the conservation of sea turtles. IUCN/SSC Marine Turtle Specialist Group Publication. No. 4. pp. 115-120.

Arthur, K. E., Boyle, M. C., Limpus, C. J. 2008. Ontogenetic changes in diet and habitat use in green sea turtles (Chelonia mydas) life history. Marine Ecology Progress Series 362: 303-311.

Avens, L. And Snover, M. L. 2013. Age and Age estimation in Sea Turtles. In: Wyneken, J., Lohmann, K.J. and Musick J.A. (Eds.). The Biology of Sea Turtles. CRC Press, pp.97134.

BALAZS, G.H. 1999. Factors to Consider in the Tagging of Sea Turtles. In: Eckert, K.L., Bjorndal, K.A., Abreu-Grobois, A. F. and Donnelly, M. (Eds.). Research and Management techniques for the conservation of sea turtles. IUCN/SSC Marine Turtle Specialist Group Publication. No. 4. pp. 101-109.

BATORI, G. 1974. Rapport d'activité. Ile tromelin. In pp. 1-15. La Réunion.

BJoRndAL, K.A. AND CARR, A. 1989. Variation in Clutch Size and Egg Size in the Green Turtle Nesting Population at Tortuguero, Costa Rica. Herpetologica, 45:181-189. Bjorndal, K.A., Wetherall, J.A., Bolten, A.B. And Mortimer, J.A. 1999. Twenty-six Years of Green Turtle Nesting at Tortuguero, Costa Rica: An Encouraging Trend. Conservation Biology, 13:126-134.

Bolten, A.B. 1999. Techniques for measuring sea turtles. Pages 110-114 in K.L. Eckert, K.A. Bjorndal, F.A. Abreu Grobois and M. Donnelly (editors). Management and Research Techniques for the Conservation of Sea Turtles. IUCN, Gland, Switzerland. Bolten_Tech_Man_1999.pdf

Bolten, A.B., Crowder, L.B., Dodd, M.G., MacPherson, S.L., Musick, J.A., Schroeder, B.A., Witherington, B.E., LONG, K.J. AND SNOVER, M.L. 2011. Quantifying multiple threats to endangered species: an example from loggerhead sea turtles. Frontiers in Ecology and the Environment, 9:295-301. 
Bosc, P. AND LE GALL, J.-Y. 1986. Attachement spatial des tortues vertes Chelonia mydas aux plages de l'île de Tromelin ( Océan Indien ). Oceanologica acta, 9:489-495.

BOURJEA, J., CiCCIONE, S. AND LAURET-STEPLER, M. 2011. Les îles Éparses : vingt-cinq ans de recherche sur les tortues marines. Bulletin Société herpéthologique Française, 139:94-111.

Bourjea, J., Ciccione, S. And Ratsimbazafy, R. 2006. Marine Turtles Surveys in Nosy Iranja Kely, North-Western Madagascar. Western Indian Ocean Journal Marine Science, 5:209-212.

Bourjea, J., Clermont, S., Delgado, A., Murua, H., Ruiz, J., Ciccione, S. And Chavance, P. Submitted b. Marine turtle interaction with purse-seine fishery in the Atlantic and Indian Oceans : lessons for management. Biological Conservation.

Bourjea, J., Frappier, J., Quillard, M., Ciccione, S., Roos, D., Hughes, G.R. And Grizel, H. 2007. Mayotte Island: another important green turtle nesting site in the southwest Indian Ocean. Endangered Species Research, 3:273-282.

Bourjea, J., Marmoerx, C., M’Soili, A., Beudard, F., Frazier, J., Roos, D. And Ciccione, S. Submitted a. Seasonality and increase in green turtle (Chelonia mydas) nesting activity at Mohéli island, Comoro archipelago, Indian Ocean. Endangered Species Research.

BourJea, J., Nel, R., Jiddawi, N.S., Koonjul, M.S. And Bianchi, G. 2008. Sea Turtle Bycatch in the West Indian Ocean : Review, Recommendations and Research Priorities. Western Indian Ocean Journal Marine Science, 7:137-150.

Bowen, B. W. AND KarL, S. A. 2007. Population genetics and phylogeography of sea turtles. Molecular Ecology, 16:4886-4907.

Broderick, A.C., Frauenstein, R., Glen, F., Hays, G.C., Jackson, A.L., Pelembe, T., RuXTON, G.D. AND GODLEY, B.J. 2006. Are green turtles globally endangered? Global Ecology and Biogeography, 15:21-26.

Broderick, A.C., Glen, F., Godley, B.J. And Hays, G.C. 2003. Variation in reproductive output of marine turtles. Journal of Experimental Marine Biology and Ecology, 288:95109.

Broderick, A.C., Godley, B.J. AND HAYs, G.C. 2001. Trophic status drives interannual variability in nesting numbers of marine turtles. Proceedings of The Royal Society / Biological sciences, 268:1481-1487.

CARR, A. AND CARR, M.H. 1970. Modulated Reproductive Periodicity in Chelonia. Ecology, $51: 335-337$. 
ChALOUPKA, M.Y. 2001. Historical trends, seasonality and spatial synchrony in green sea turtle egg production. Biological Conservation, 101:263-279.

Cheng, I., Huang, C., Hung, P., Ke, B. And Kuo, C. 2009. Ten Years of Monitoring the Nesting Ecology of the Green Turtle, Chelonia mydas, on Lanyu (Orchid Island), Taiwan. Zoological studies, 48:83-94.

Ciccione, S. And BourJeA, J. 2006. Nesting of Green Turtles in Saint Leu, Réunion Island. Marine Turtle Newsletter, 1-3.

LE CORRE, M. 1996. The breedinc seabirds of tromelin island (western indian ocean): population sizes, trends and breeding phenology. Ostrich, 67:155-159.

Le CorRe, M. And Jouventin, P. 1997. Kleptoparasitism in Tropical Seabirds: Vulnerability and Avoidance Responses of a Host Species, the Red-Footed Booby. The Condor, 99:162-168.

LE CORRE, M. AND SAFFORD, R.J. 2001. La Réunion and Iles Eparses. In: Important Birds Areas in Africa and associated islands. pp. 693-702.

DALlEAU, M. 2013. Ecologie spatiale des tortues marines dans le Sud-Ouest de l'Océan Indien. Apport de la géomatique et de la modélisation pour la conservation. Doctoral thesis. Université de La Réunion.

Dalleau, M., Ciccione, S., Mortimer, J.A., Garnier, J., Benhamou, S. And Bourjea, J. 2012. Nesting phenology of marine turtles: insights from a regional comparative analysis on green turtle (Chelonia mydas). PloS one, 7:e46920.

DIREN 2003. Document de prise en considération pour le classement des îles Eparses en réserve naturelle nationale. Saint Denis, La Réunion.

FraIN, I. 2009. Les naufragés de l'île Tromelin. In: Lafon, M. (Eds.). 371 pp.

FrazIER, J. 1985. Marine turtles in the Comoros Archipelago. North-Holland Publishing Company, Amsterdam.

FrAZIER, J. 2012. Nest and Track Surveys. In: McDiarmid, R.W., Foster, M.S., Guyer, C., Gibbons W.J. and Chernoff N. ( Eds.). Reptile Biodiversity. University of California Press, Los Angeles, pp. 260-271.

FuENTES, M.M.P.B., LimPUS, C.J. AND HAMANN, M. 2011. Vulnerability of sea turtle nesting grounds to climate change. Global Change Biology, 17:140-153.

Le Gall, J.-Y., Bosc, P., Chateau, D. And Taquet, M. 1986. Estimation du nombre de tortues vertes femelles adultes Chelonia mydas par saison de ponte à Tromelin et Europa (1973-1985). Océanographie tropicale, 21:3-22. 
LE GALl, J.-Y. AND HugheS, G.R. 1987. Migrations de la tortue verte Chelonia mydas dans l'Océan Indien Sud-Ouest observées à partir de marquages sur les sites de ponte Europa et Tromelin (1970-1985). Amphibia-Reptilia, 8:277-282.

LE GALL, J.-Y., LEBEAU, A. AND KoPP, J. 1985. Évaluation de la production de tortues vertes Chelonia mydas nouveau-nées sur les sites de ponte Europa et Tromelin. Océanographie tropicale, 2:117-133.

LE GALl, N. AND POUPIN, J. undated. CRUSTA: Database of Crustacea (Decapoda and Stomatopoda), with special interest for those collected in French overseas territories. Http://crustiesfroverseas.free.fr/. Accessed 26 May 2014.

Garnier, J., Hill, N., Guissamulo, A., Silva, I., Witt, M. And Godley, B.J. 2012. Status and community-based conservation of marine turtles in the northern Querimbas Islands (Mozambique). Oryx, 46:359-367.

Gerodette, T. And TAylor, B.L. 1999. Estimating Population Size. In: Eckert, K.L., Bjorndal, K.A., Abreu-Grobois, A. F. and Donnelly, M. (Eds.). Research and Management techniques for the conservation of sea turtles. IUCN/SSC Marine Turtle Specialist Group Publication. No. 4. pp. 67-71.

GODLEY, B.J., THOMPSON, N.S., WALDRON, S. AND FuRNESS, R.W. 1998. The trophic status of marine turtles as determined by stable isotope analysis. Marine Ecology Progress Series, 166:277-284.

Harris, A., Manahira, G., Sheppard, A., Gough, C. And Sheppard, C. 2010. Demise of Madagascar's once great barrier reef-Change in coral reef condition over 40 years. Atoll Research Bulletin, pp. 1-16.

HAYS, G.C. 2000. The implications of variable remigration intervals for the assessment of population size in marine turtles. Journal of theoretical biology, 206:221-227.

Hughes, G.R. 1974. The sea turtles of south East Africa I- Status, morphology and distribution. Investigational report 35. Durban, South Africa, $144 \mathrm{pp}$.

Hughes, G.R. 1982. Conservation of Sea Turtles in the Southern Africa Region. In: Bjorndal, K.A. (Eds.). Proc. World Conference on Sea Turtle Conservation. Smithonian Institution Press Books, Washington, pp. 397-404.

Hughes, R.A., Williams, S.L., Duarte, C.M., Heck, K.L. And Waycott, M. 2009. Associations of concern: declining seagrasses and threatened dependent species. Frontiers in Ecology and the Environment, 7:242-246. 
Humber, F., Godley, B.J., RAMAhery, V. AND Broderick, A.C. 2011. Using community members to assess artisanal fisheries: the marine turtle fishery in Madagascar. Animal Conservation, 14:175-185.

IUCN RED LIST OF THREATENED SPECIES. Green turtle (Chelonia mydas) http://www.iucnredlist.org/, Published 30 April 2004. Accessed 30 May 2014.

Jackson, A.L., Broderick, A.C., Fuller, W.J., Glen, F., RuXton, G.D. AND Godley, B.J. 2008. Sampling design and its effect on population monitoring: How much monitoring do turtles really need? Biological Conservation, 141:2932-2941.

JENNINGS, S. 2000. Patterns and prediction of population recovery in marine reserves. Reviews in Fish Biology and Fisheries, 10:209-231.

Lauret-Stepler, M., Bourjea, J., Roos, D., Pelletier, D., Ryan, P.G., Ciccione, S. AND GRIZEL, H. 2007. Reproductive seasonality and trend of Chelonia mydas in the SW Indian Ocean: a 20 yr study based on track counts. Endangered Species Research, 3:217227.

Limpus, C.J., Miller, J.D., PARMEnTER, J.C. And LimPus, D.J. 2003. The green turtle, Chelonia mydas, population of Raine Island and the northern great barrier reef: 18432001. Memoirs of the Queensland Museum, 49:349-440.

MARriner, N., GuÉROUt, M., RomOn, T. AND Dussouillez, P. 2010. Géomorphologie de Tromelin, océan Indien. Comptes Rendus Geoscience, 342:766-777.

Mast, R.B., Hutchinson, B.J., Howgate, E. And Pilcher, N.J. 2005. MTN 110:13-15 MTSG UPDATE: IUCN/SSC Marine Turtle Specialist Group Hosts the Second Burning Issues Assessment Workshop. Marine Turtle Newsletter. http://www.seaturtle.org/mtn/archives/mtn110/mtn110p13.shtml. Accessed 24 April 2014.

MiLler, J.D. 1997. Reproduction in sea turtles. In: The Biology of Sea Turtles (eds Lutz PL, Musick JA), pp. 51-81. CRC Press, Boca Raton, Florida.

MiLLER, J.D. 1999. Determining Clutch Size and Hatching Success. In: Eckert, K.L., Bjorndal, K.A., Abreu-Grobois, A. F. and Donnelly, M. (Eds.). Research and Management techniques for the conservation of sea turtles. IUCN/SSC Marine Turtle Specialist Group Publication. No. 4. pp. 124-130.

Mortimer, J.A. 1988. Green Turtle nesting at aldabra atoll-Population estimates and trends. Biology Society Washinghton, 8:116-128. 
MorTimer, J.A. 1990. The Influence of Beach Sand Characteristics on the Nesting Behaviour and Clutch Survival of Green Turtles (Chelonia mydas). Copeia, 3:802-817.

Mortimer, J.A. 1999. Temporal Distribution and Periodicity in Hawksbill turtles nesting at Cousin Island, Republic of Seychelles, 1971-1997. Chelonian Conservation and Biology, $3: 318-325$.

Mortimer, J.A. 2012. ASeasonality of Green Turtle (Chelonia mydas) Reproduction at Aldabra Atoll, Seychelles (1980-2011) in the Regional Context of the Western Indian Ocean. Chelonian Conservation and Biology, 11:170-181.

Mortimer, J.A., Brandis, R.G. Von, LiLjevik, A., Chapman, R. And Collie, J. 2011. Fall and Rise of Nesting Green Turtles ( Chelonia mydas ) at Aldabra Atoll, Seychelles : Positive Response to Four Decades of Protection ( 1968 - 2008 ). Chelonian Conservation and Biology, 10:165-176.

Orth, R.J., Carruthers, T.I.M.J.B., Dennison, W.C., Duarte, C.M., James, W., Heck, K.L., Hughes, R.A., Kendrick, G.A., Kenworthy, J.K., Olyarnik, S., Short, F.T., Waycott, M. AND WiLliams, S.L. 2006. A Global Crisis for Seagrass Ecosystems. Bioscience, 56:987-996.

PIKE, D.A. 2008. Environmental correlates of nesting in loggerhead turtles, Caretta caretta. Animal Behaviour, 76:603-610.

Pritchard, P.C.H. AND Mortimer, J.A. 1999. Taxonomy, External Morphology, and Species Identification. In: Eckert, K.L., Bjorndal, K.A., Abreu-Grobois, A. F. and Donnelly, M. (Eds.). Research and Management techniques for the conservation of sea turtles. IUCN/SSC Marine Turtle Specialist Group Publication. No. 4. pp. 21-38.

R CORE TEAM 2013. R: A language and environment for statistical computing. R Foundation for Statistical Computing, Vienna, Austria.

RAKOTONIRINA, B. AND COOKE, A. 1994. Sea turtles of Madagascar - their status, exploitation and conservation. Oryx, 28: 51:61.

Rivalan, P., Pradel, R., Choquet, R., Girondot, M. And Prévot-Julliard, A.-C. 2006. Estimating clutch frequency in the sea turtle Dermochelys coriacea using stopover duration. Marine Ecology Progress Series, 317:285-295.

Russell, J.C. AND LE CORRE, M. 2009. Introduced mammal impacts on seabirds in the îles Eparses, western indian ocean. Marine Ornithology, 37:121-128.

SCHRoEder, B.A. AND MurPhy, S. 1999. Population Surveys ( ground and aerial ) on Nesting Beaches. In: Eckert, K.L., Bjorndal, K.A., Abreu-Grobois, A. F. and Donnelly, M. 
(Eds.). Research and Management techniques for the conservation of sea turtles.

IUCN/SSC Marine Turtle Specialist Group Publication. No. 4. pp. 45-55.

Vergonzanne, G., Servan, J. AND BATORI, G. 1976. Biology of the green turtle on the Iles

Glorieuses, Europa and Tromelin. In ORSTOM. Paris, France.

Wallace, B.P., DiMatteo, A.D., Bolten, A.B., Chaloupka, M.Y., Hutchinson, B.J., Abreu-Grobois, F.A., Mortimer, J.A., Seminoff, J.A., Amorocho, D.F., Bjorndal, K.A., Bourjea, J., Bowen, B.W., Briseño Dueñas, R., Casale, P., Choudhury, B.C., Costa, A., Dutton, P.H., Fallabrino, A., Finkbeiner, E.M., Girard, A., Girondot, M., Hamann, M., Hurley, B.J., LóPez-Mendilaharsu, M., Marcovaldi, M.A., Musick, J.A., Nel, R., Pilcher, N.J., Trö̈ng, S., Witherington, B.E. And Mast, R.B. 2011. Global conservation priorities for marine turtles. PloS one, 6:e24510.

Wallace, B.P., Lewison, R.L., McDonald, S.L., McDonald, R.K., Kot, C.Y., Kelez, S., BjorKland, R.K., FinkBeiner, E.M., Helmbrecht, S. AND Crowder, L.B. 2010.

Global patterns of marine turtle bycatch. Conservation Letters, 3:131-142. 
Table 1. Comparison of nesting characteristics of green turtles nesting on Tromelin Island for approximatively a 3-month period coinciding with the 1973/1974 to 1983/1984 nesting peaks and the 2009/2010 nesting peak. During the nesting seasons 1973/1974 (Batori 1974 in Le Gall et al. 1985), 1981/1982, 1982/1983 and 1983/1984 (Le Gall et al. 1985, 1986), data was collected over three- to four-months study periods centred on December. Maximum and minimum values are provided for the 1973-1984 nesting (min-max).

\begin{tabular}{|lcc|}
\hline Nesting characteristics & $\begin{array}{c}\mathbf{2 0 0 9 / 2 0 1 0 ~ n e s t i n g ~} \\
\text { peak }\end{array}$ & $\begin{array}{c}\text { 1973 - 1984 nesting peaks } \\
\text { (Le Gall et al. 1985, 1986) }\end{array}$ \\
\hline Population nesting success & 0.65 & $0.41-0.65$ \\
Number of nests & 2750 & $2857-3260$ \\
Population clutch frequency & 2.75 & $2.31-3.39$ \\
Standard deviation & 1.46 & - \\
Sample size & 424 & - \\
\hline
\end{tabular}


Table 2. Comparison of clutch size and fate of green turtles nests on Tromelin Island. For the 1971 to 1984 period, maximum and minimum values found over all nesting peaks are given (min-max).

\begin{tabular}{|c|c|c|}
\hline Nest indices & $2009 / 2010$ nesting season & $\begin{array}{l}1971-1984 \text { nesting peaks } \\
\text { (Le Gall et al. 1985, 1986) }\end{array}$ \\
\hline Clutch size $^{a}$ & 109 & $132-136$ \\
\hline Standard deviation & 23.5 & $15.5-25.4$ \\
\hline Sample size & 96 & $34-43$ \\
\hline Hatching success ${ }^{b}$ & 0.76 & 0.76 \\
\hline Standard deviation & 0.25 & 0.21 \\
\hline Sample size & 96 & 30 \\
\hline Emergence success ${ }^{a}$ & 0.61 & $0.36-0.77$ \\
\hline Standard deviation & 0.33 & $0.09-0.19$ \\
\hline Sample size & 73 & $6-34$ \\
\hline
\end{tabular}
1981/1982, 1982/1983 and 1983/1984 (Le Gall et al. 1985) on three to four-month long study periods centred on December.

${ }^{b}$ Data collected during the nesting season 1971/1972 (Hughes 1974 in Le Gall et al. 1985) 
Table 3. Comparison of population size and production estimates of green turtles nesting on Tromelin for 3-month periods during peak nesting. Estimations made for the periods centred on December of nesting seasons 1973/1974, 1981/1982, 1982/1983, 1983/1984 and the 2009/2010 nesting peak. In the case of the 1973 to 1984 period, maximum and minimum estimates and standard deviations found over all nesting peaks are given rounded up to the nearest hundred (min - max).

\begin{tabular}{|lcc|}
\hline $\begin{array}{c}\text { Population and production } \\
\text { estimates }\end{array}$ & $\begin{array}{c}\mathbf{2 0 0 9 / 2 0 1 0} \\
\text { nesting peak }\end{array}$ & $\begin{array}{c}\text { 1973 - 1984 nesting peaks (Le } \\
\text { Gall et al. 1985, 1986) }\end{array}$ \\
\hline Estimated number of females & 999 & $700-1400$ \\
Estimated egg production & 299,406 & $380,200-450,500$ \\
Standard deviation & 64,687 & $43,100-49,800$ \\
Estimated hatchling production & 180,069 & $152,600-309,700$ \\
Standard deviation & 94,651 & $36,300-59,600$ \\
\hline
\end{tabular}




\section{Figure Captions}

Figure 1. Location of Tromelin Island in the South-Western Indian Ocean and detailed mapping of the study site.

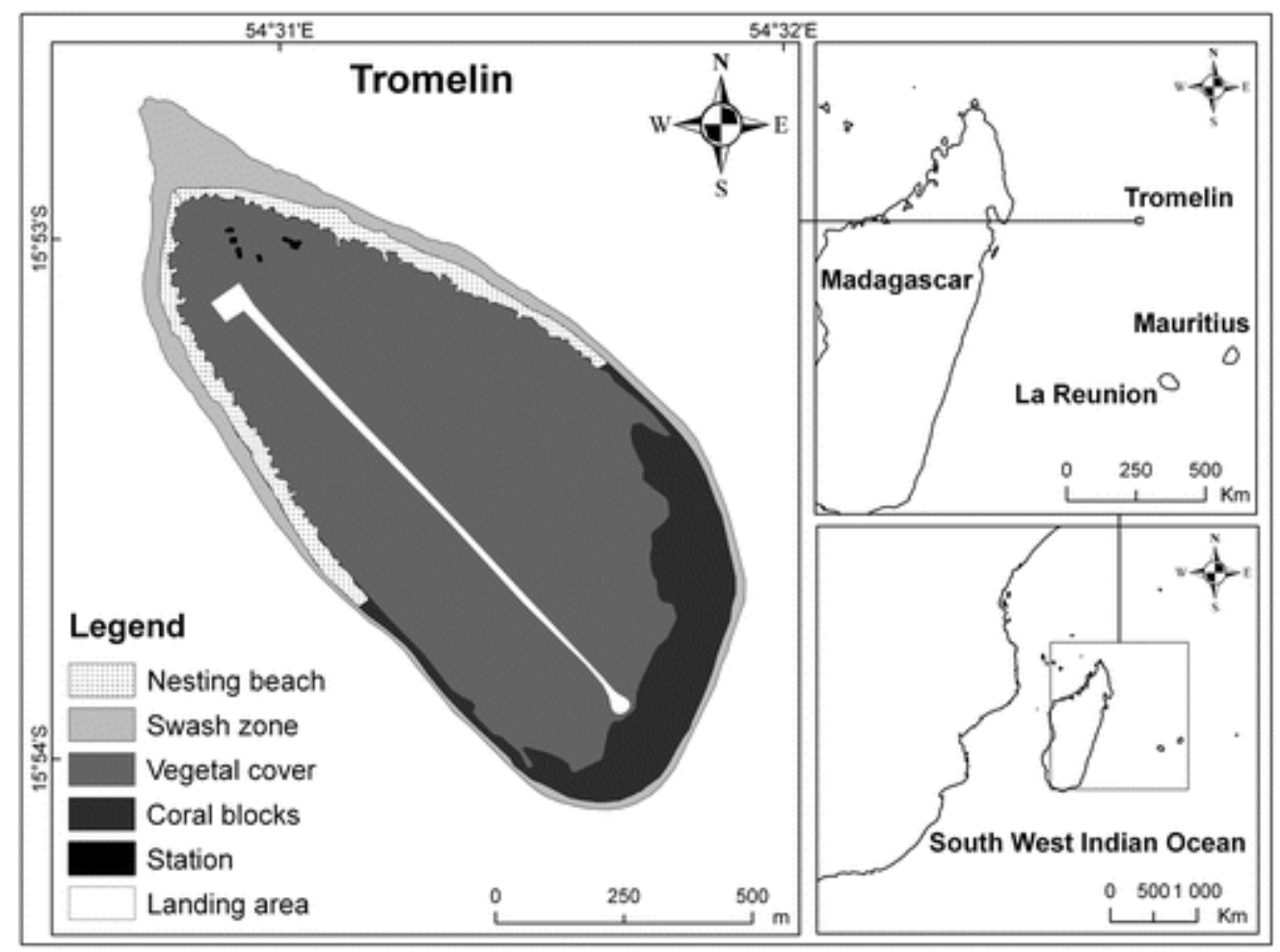

Figure 2. Interpolated seasonal track counts on Tromelin Island from 1986/1987 to 2009/2010. Nesting seasons showing daily track count gaps greater than one month were not included (e.g., 2008/2009).

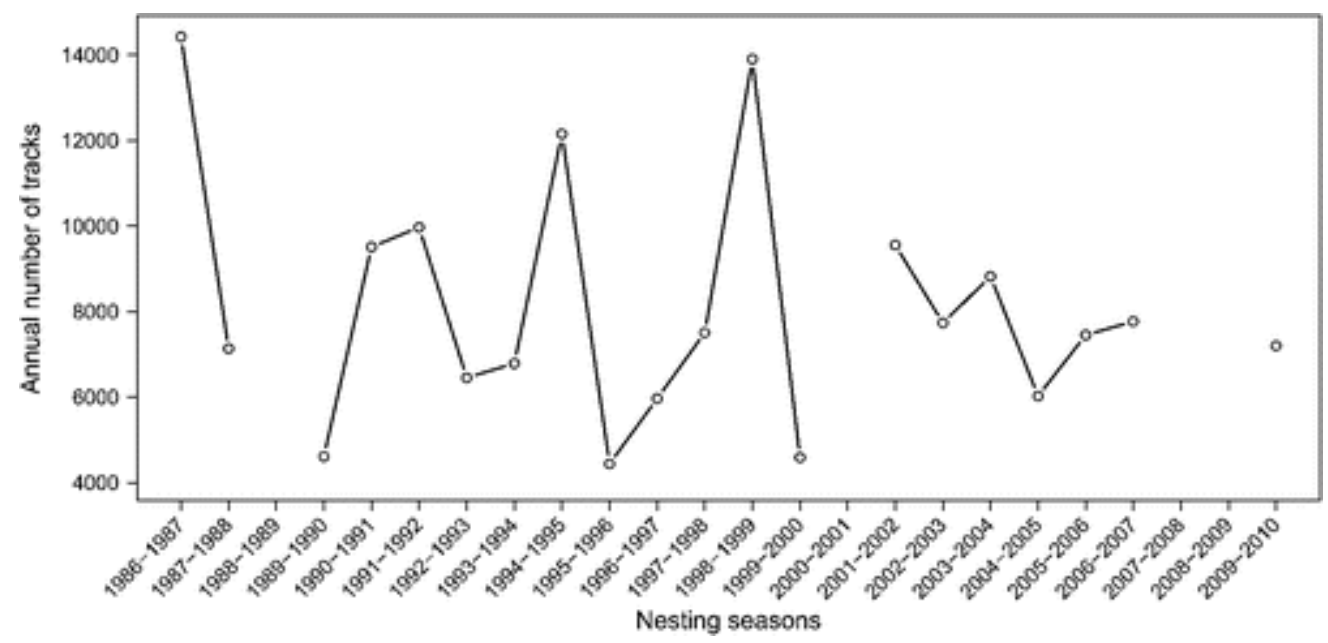


Figure 3. Distribution of recapture intervals of green turtles nesting on Tromelin Island during the 2009/2010 nesting peak. Dotted line: gaussian kernel density estimate with bandwidth=1.8. Algorithm for density smoothing is based on a Fast Fourier Transform.

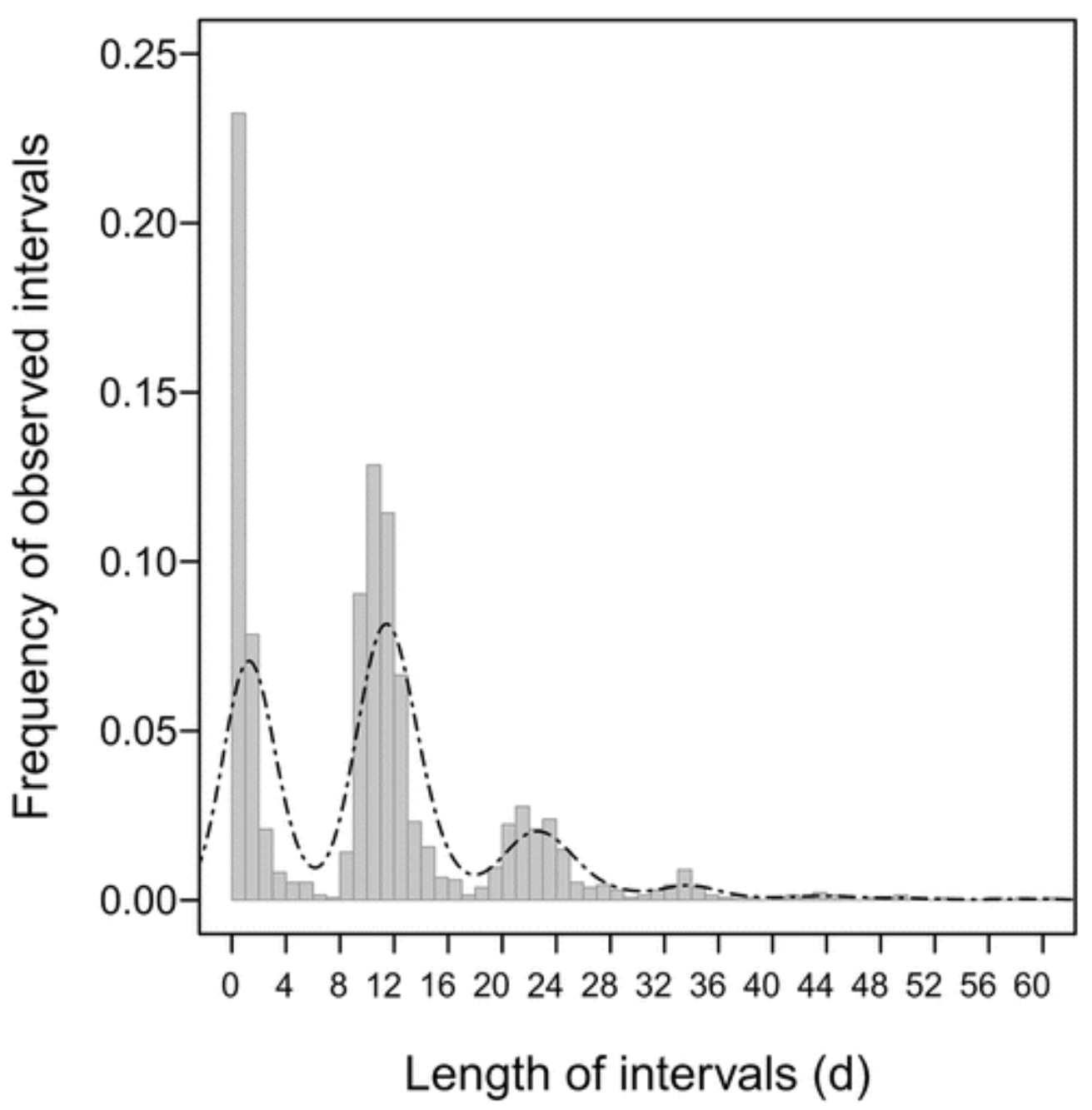

